\title{
ESTUDO ULTRA-ESTRUTURAL DO PROCESSO REMIELINIZANTE PÓS-INJEÇÃO DE BROMETO DE ETÍDIO NO TRONCO ENCEFÁLICO DE RATOS IMUNOSSUPRIMIDOS COM DEXAMETASONA
}

\author{
Eduardo Fernandes Bondan', Maria Anete Lallo, ,2, Erika Infante Baz', \\ Idércio Luís Sinhorini ${ }^{3}$, Dominguita Luhers Graça ${ }^{4}$
}

\begin{abstract}
RESUMO - Linfócitos estão presentes nas lesões desmielinizantes induzidas pelo brometo de etídio (BE) no sistema nervoso central (SNC) e a possibilidade de sua participação em eventuais respostas imunomediadas às bainhas de mielina desprendidas não pode ser descartada. Este estudo objetivou investigar as conseqüências da imunossupressão com dexametasona no reparo do SNC após injeção local de BE. Ratos Wistar adultos receberam 10 microlitros de solução de $\mathrm{BE}$ a $0,1 \%$ na cisterna pontis. Alguns destes foram tratados intraperitonealmente com dexametasona ( $3 \mathrm{mg} / \mathrm{kg} / \mathrm{dia}$, grupo I, $\mathrm{n}=15$ ) durante o período experimental; outros não foram imunossuprimidos (grupo $I I, n=15$ ). Animais de ambos os grupos foram perfundidos com solução fixadora de glutaraldeído a 4\% aos 7,11,15,21 e 31 dias pós-injeção de BE. Fragmentos do tronco encefálico foram colhidos e processados para estudos de microscopia eletrônica de transmissão. Os ratos do grupo I apresentaram maiores quantidades de membranas derivadas de mielina que os não-imunossuprimidos (grupo II), sugerindo um atraso na atividade macrofágica de retirada dos restos mielínicos. Raros linfócitos foram encontrados. A atividade remielinizante oligodendroglial também mostrou um padrão retardado, com claro predomínio de axônios desmielinizados.
\end{abstract}

PALAVRAS-CHAVE: brometo de etídio, dexametasona, imunossupressão, ratos, remielinização, sistema nervoso central.

Ultrastructural study of the remyelinating process following local ethidium bromide injection in the brainstem of dexamethasone-immunosuppressed rats

\begin{abstract}
Lymphocytes are present within ethidium-bromide (EB)-demyelinated lesions in the central nervous system (CNS) and the possibility of its participation in accidental immune-mediated responses to the detached myelin sheaths can not be ruled out. This study aimed to investigate the consequences of immunosuppression with dexamethasone in CNS repair after local EB injection. Adult Wistar rats received 10 microlitres of $0.1 \%$ EB solution into the cisterna pontis. Some were treated intraperitoneally with dexamethasone ( $3 \mathrm{mg} / \mathrm{kg} /$ day, group $\mathrm{l}, \mathrm{n}=15$ ) during the experimental period; others were not immunosuppressed (group II, $n=15$ ). Animals from both groups were perfused with $4 \%$ glutharaldehyde at 7,11,15,21 and 31 days following EB injection. Brainstem slices were collected and processed for transmission electron microscopy studies. Rats from group I showed greater amounts of myelin-derived membranes than nonimmunosuppressed rats (group II), suggesting a delay in the macrophagic activity of removing myelin debris. Rare lymphocytes were found. Oligodendrocyte remyelinating activity also showed a delayed pattern, with clear predominance of naked axons.
\end{abstract}

KEY WORDS: ethidium bromide, dexamethasone, immunosuppression, rats, remyelination, central nervous system.

Acredita-se que a falta de remielinização completa em algumas doenças desmielinizantes do sistema nervoso central (SNC) possa ocorrer devido à presença de fatores inibidores que evitam a expressão plena do reparo mielínico ou pela ausência de fatores requeridos para a reconstrução das bainhas perdidas ${ }^{1}$. Estas hipóteses levam à crença de que, uma vez identificados tais fatores, a rápida intervenção, tanto para estimular aqueles elementos que conduzem à remielinização como tam-

\footnotetext{
'Universidade Bandeirante de São Paulo, São Paulo SP, Brasil; '2Universidade Paulista (UNIP), São Paulo SP, Brasil; ${ }^{3}$ Departamento de Patologia Veterinária Faculdade de Medicina Veterinária e Zootecnia (FMVZ), Universidade de São Paulo (USP), São Paulo SP, Brasil; ${ }^{4}$ Departamento de Patologia, Universidade Federal de Santa Maria (UFSM), Santa Maria RS, Brasil.
} 
bém para remover aqueles que são inibidores desse reparo, representará a chave para a manipulação terapêutica das doenças desmielinizantes ${ }^{1}$. Nesse sentido, diversos estudos têm sido desenvolvidos a partir de modelos experimentais, visando identificar fatores, drogas e procedimentos capazes de, direta ou indiretamente, influenciar de alguma forma a biologia do processo de desmielinização e remielinização no SNC. Um achado importante no modelo desmielinizante do brometo de etídio $(B E)^{2-9}$ foi a constatação de que, na maioria das lesões entre 3 e 31 dias pós-injeção do gliotóxico, os linfócitos estavam presentes, contactando macrófagos carregados de mielina ou as próprias bainhas em degeneração ${ }^{6}$. A razão da presença linfocitária permanece desconhecida, podendo ser explicada simplesmente como parte da resposta inflamatória geral induzida no tecido pela droga; ou como partícipe do reconhecimento antigênico de frações mielínicas antes mascaradas e agora expressas pelo desprendimento das lamelas pós-injeção do gliotóxico; ou, por fim, exercendo algum papel efetor em possíveis respostas imunomediadas à quebra das bainhas de mielina ${ }^{6}$.

O desenvolvimento de estratégias terapêuticas capazes de inibir a desmielinização e/ou acelerar a remielinização tem recebido especial atenção na pesquisa em progresso a respeito das doenças desmielinizantes, uma vez que a maioria dos tratamentos utilizados na atualidade são desenvolvidos visando suprimir componentes patogênicos hipotetizados, como o sistema imune, e são apenas paliativos. Como agentes imunossupressores e antiinflamatórios são comumente empregados de forma inespecífica no seu tratamento, torna-se de fundamental importância estabelecer de forma precisa os efeitos particulares das drogas utilizadas na rotina clínica neurológica sobre a biologia do processo desmielinizante e remielinizante do SNC.

Partindo de estudos que permitiram estabelecer a influência de imunossupressores como a ciclofosfamida e a ciclosporina sobre o processo de remielinização pós-injeção do $\mathrm{BE}^{10-12}$, torna-se importante estudar como outras drogas moduladoras da função imune, tais como o esteróide antiinflamatório dexametasona (Dx), comumente empregado na clínica neurológica, afetaria a perda e restauro das bainhas de mielina nesse modelo. Dessa forma, o presente estudo teve como objetivo investigar morfologicamente os eventos celulares envolvidos na tentativa de interferência farmacológica com a Dx no processo de desmielinizaçãoremielinização do tronco encefálico de ratos Wistar submetidos ao modelo experimental do $\mathrm{BE}$, comparando-se os resultados obtidos com aqueles observados em animais não-tratados.

\section{MÉTODO}

Foram utilizados 35 ratos Wistar, machos, de 4 a 6 meses de idade ao início do experimento, mantidos em caixas com maravalha esterilizada por autoclavagem $\left(130^{\circ} \mathrm{C}\right.$ por 20 minutos) e trocada 3 vezes por semana. Receberam ad libitum água e ração peletizada também esterilizadas. Destes, 30 animais receberam diariamente, durante todo período experimental, $3 \mathrm{mg} / \mathrm{kg}$ de dexametasona (Dx - via intraperitoneal).

Os ratos foram divididos em 3 grupos - I ( $n=15)$, compreendendo animais injetados na cisterna basal com solução de BE a 0,1\% e imunossuprimidos com Dx; II $(n=15)$, de ratos igualmente injetados com BE e nãotratados com Dx (imunocompetentes); e III $(n=5)$, de animais injetados com solução salina a 0,9\% e tratados com Dx.

Os animais foram anestesiados com quetamina e xilazina $(5: 1,0,1 \mathrm{ml} / 100 \mathrm{~g})$ e, com auxílio de um motor de teto, de uso odontológico, e de broca de número 2 , foi feito orifício na calota óssea a $0,85 \mathrm{~cm}$ póstero-diagonalmente e à direita do bregma até a exposição da duramáter. Com o uso de uma seringa de Hamilton, de agulha removível de calibre $26 \mathrm{~s}$, introduzida numa posição perpendicular ao plano da superfície óssea da calota craniana até atingir a base do crânio, foram injetados na cisterna pontis (basal), um alargamento do espaço subaracnoideo na superfície ventral da ponte, $10 \mu \mathrm{l}$ (microlitros) de solução de BE a $0,1 \%$ em salina a $0,9 \%$ nos animais dos grupos I e II e o mesmo volume de solução salina nos ratos do grupo III. Três animais dos grupos I e II e um do grupo III foram anestesiados e submetidos à perfusão intracardíaca com solução de glutaraldeído a $4 \%$ em tampão fosfato de Sorensen $0,1 \mathrm{M}(\mathrm{pH} 7,4)$ em cada um dos seguintes períodos pós-cirurgia - 7, 11, 15, 21 e 31 dias.

Fragmentos do tronco encefálico (ponte, mesencéfalo e corpo trapezóide) foram colhidos e pós-fixados com tetróxido de ósmio a $1 \%$, desidratados em série decrescente de acetonas e incluídos em Araldite 502, após estágios transicionais em acetona. Cortes semifinos foram feitos e corados com azul de toluidina a $0,25 \%$. Cortes ultrafinos de áreas selecionadas foram obtidos, corados com acetato de uranila a $2 \%$ e citrato de chumbo e examinados com microscópio eletrônico de transmissão Phillips EM-201.

\section{RESULTADOS}

Serão descritos os achados morfológicos relativos aos animais imunossuprimidos com Dx que receberam BE (grupo I) e salina (grupo III). Quanto aos animais injetados com BE e não-imunossuprimidos do grupo Il, observou-se que as lesões indu- 
zidas se mostraram idênticas àquelas já relatadas em estudos anteriores ${ }^{7,9-12}$ envolvendo o gliotóxico no tronco encefálico, sendo, portanto, aqui utilizados apenas para fins de comparação com as descrições morfológicas relacionadas aos ratos tratados com Dx.

\section{Observações morfológicas no grupo I}

(injetados com $B E$ e tratados com $D x$ )

À microscopia de luz, foram observadas aos 7 dias pós-injeção do BE lesões de extensão variável desde o mesencéfalo até o corpo trapezóide, porém afetando predominantemente a superfície ventral da ponte, próximo às meninges. Duas áreas podiam ser claramente visualizadas em relação à injeção do BE - uma central e outra periférica. O centro da lesão exibia um espaço extracelular expandido, preenchido por material floculento e macrófagos ativados, bem como apresentando axônios desmielinizados, isolados ou aglutinados, alguns linfócitos e algumas poucas fibras nervosas em degeneração. À microscopia eletrônica de transmissão, o material floculento observado nos cortes semifinos foi caracterizado pela presença de grandes quantidades de membranas derivadas de mielina, entremeando axônios desmielinizados e macrófagos em intensa atividade fagocítica.

Aos 11 dias, a observação mais importante foi a associação de algumas fibras nervosas a células identificadas como células de Schwann, localizadas sobretudo, mas não exclusivamente, em áreas perivasculares e subpiais da periferia da lesão, principalmente em áreas de espaço extracelular aumentado e sempre destituídas de processos astrocitários. Na periferia da lesão, foram notados alguns poucos oligodendrócitos junto a axônios desmielinizados e próximos a processos astrocitários, às vezes hipertróficos e ricos em feixes de filamentos intermediários. Poucos linfócitos foram encontrados, relacionados com restos de mielina e células fagocíticas, em localização perivascular ou profunda no neurópilo.

Aos 15 dias, persistiam no centro da lesão axônios desmielinizados entre profusas membranas derivadas de mielina e macrófagos em atividade fagocítica (Fig 1). Na periferia lesional, já podiam ser visualizados axônios dotados de finas bainhas de mielina, formadas por oligodendrócitos (Fig 2A) ou por células de Schwann, na dependência da presença ou não de processos astrocitários associados. As bainhas de origem oligodendroglial mostravamse ainda muito delgadas e dotadas de lamelas mal compactadas. Por sua vez, as células de Schwann apresentavam-se em fase mais avançada de deposição mielínica, ainda que algumas ainda estivessem associadas com um ou vários axônios desmielinizados, num espaço extracelular expandido, no qual eram visualizadas numerosas fibras colágenas (Fig 2B). Não era possível identificar o tipo de remielinização predominante, se por oligodendrócitos ou por células de Schwann, embora se tenha notado claramente que as últimas possuíam maior rapidez de deposição de mielina do que as primeiras. No entanto, apesar da ocorrência desse processo remielinizante nos bordos da lesão, ainda se observava o maciço predomínio de axônios desmielinizados. Processos astrocitários ligeiramente tumefeitos também podiam ser encontrados, envolvendo axônios desmielinizados, alguns poucos axônios em degeneração e restos de mielina no espaço extracelular. Adicionalmente, foram encontrados capilares neoformados e grupamentos, às vezes extensos, de células piais infiltrantes, mas não mais linfócitos.

Em relação aos achados do $21^{\circ}$ dia nos animais imunocompetentes, aqueles tratados com Dx apresentaram no mesmo período considerável atraso no processo de reparo da lesão. À microscopia de luz já era possível observar que os animais que haviam recebido $D x$ exibiam maior persistência de material finamente floculento no espaço extracelular amplamente distendido da área central. Além

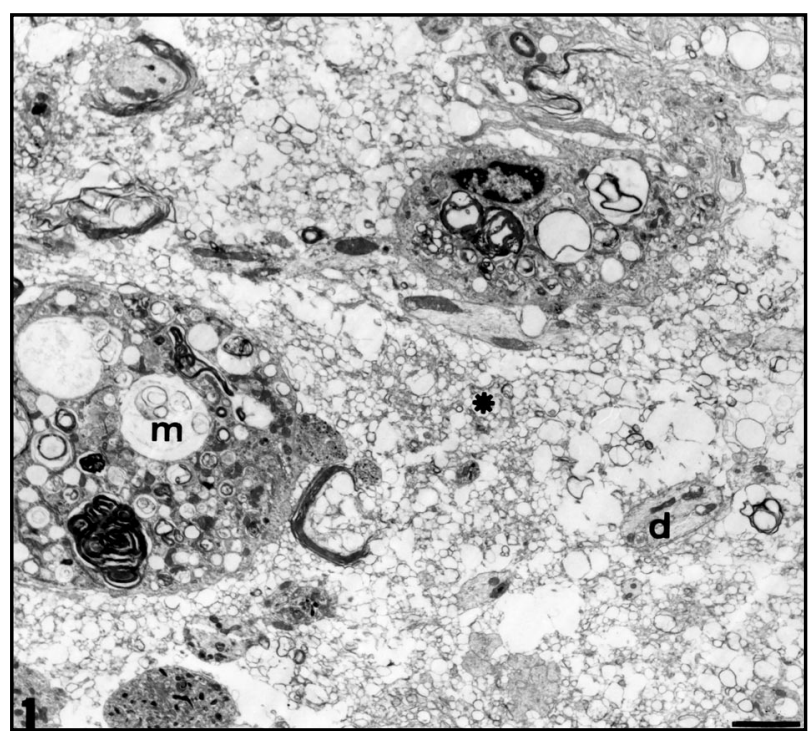

Fig 1. Macrófagos ativados (m), contendo mielina em diferentes estágios de degradação (desde a visualização de lamelas recém fagocitadas até glóbulos de gordura neutra), entre axônios desmielinizados (d) e grande quantidade de membranas derivadas de mielina no espaço extracelular (*). Centro lesional aos 15 dias. Grupo I. Micrografia eletrônica. Barra = 2,2 $\mu \mathrm{m}$. 


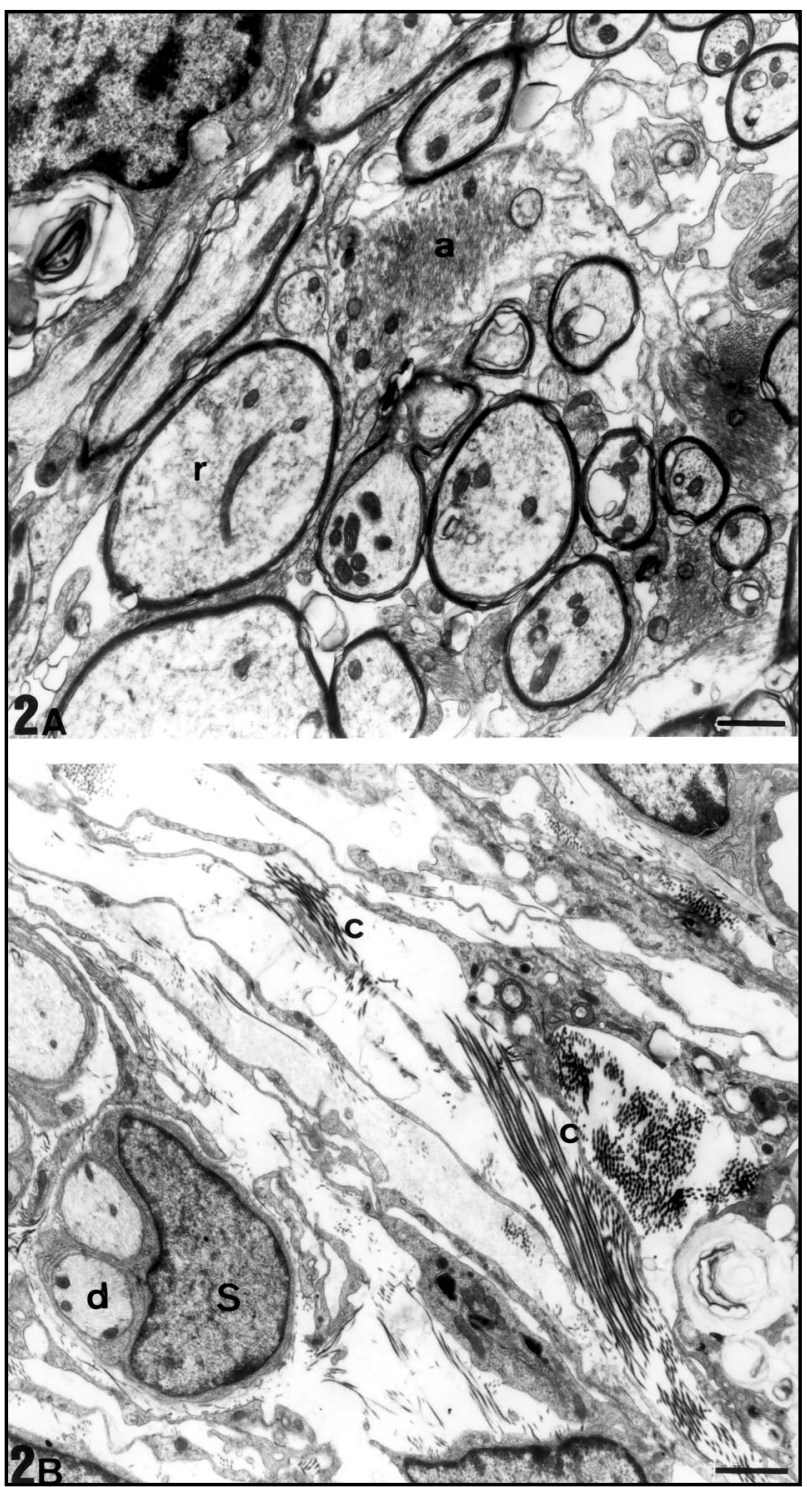

Fig 2. A) Axônios remielinizados por oligodendrócitos ( $r$ ) próximos a processos astrocitários (a) na periferia lesional. $B$ ) Células de Schwann (s) em estágios iniciais de associação com axônios desmielinizados (d) num espaço extracelular expandido e repleto de fibras colágenas (c). Lesão de 15 dias. Grupo I. Micrografias eletrônicas. A e B) Barra =0,96 $\mu \mathrm{m}$.

disso, a proporção de axônios desmielinizados e de células piais presentes mostrava-se acentuadamente maior que nos animais injetados com BE e não-imunossuprimidos. A remielinização de origem oligodendroglial apresentava-se aparentemente menos extensa e com bainhas mais finas do que aquela encontrada no mesmo período em animais não-tratados. Já com relação ao reparo mielínico feito por células de Schwann, não foram notadas diferenças significativas entre os animais de ambos os grupos quanto à capacidade de restauro das bainhas perdidas. As células de Schwann situavam-se em

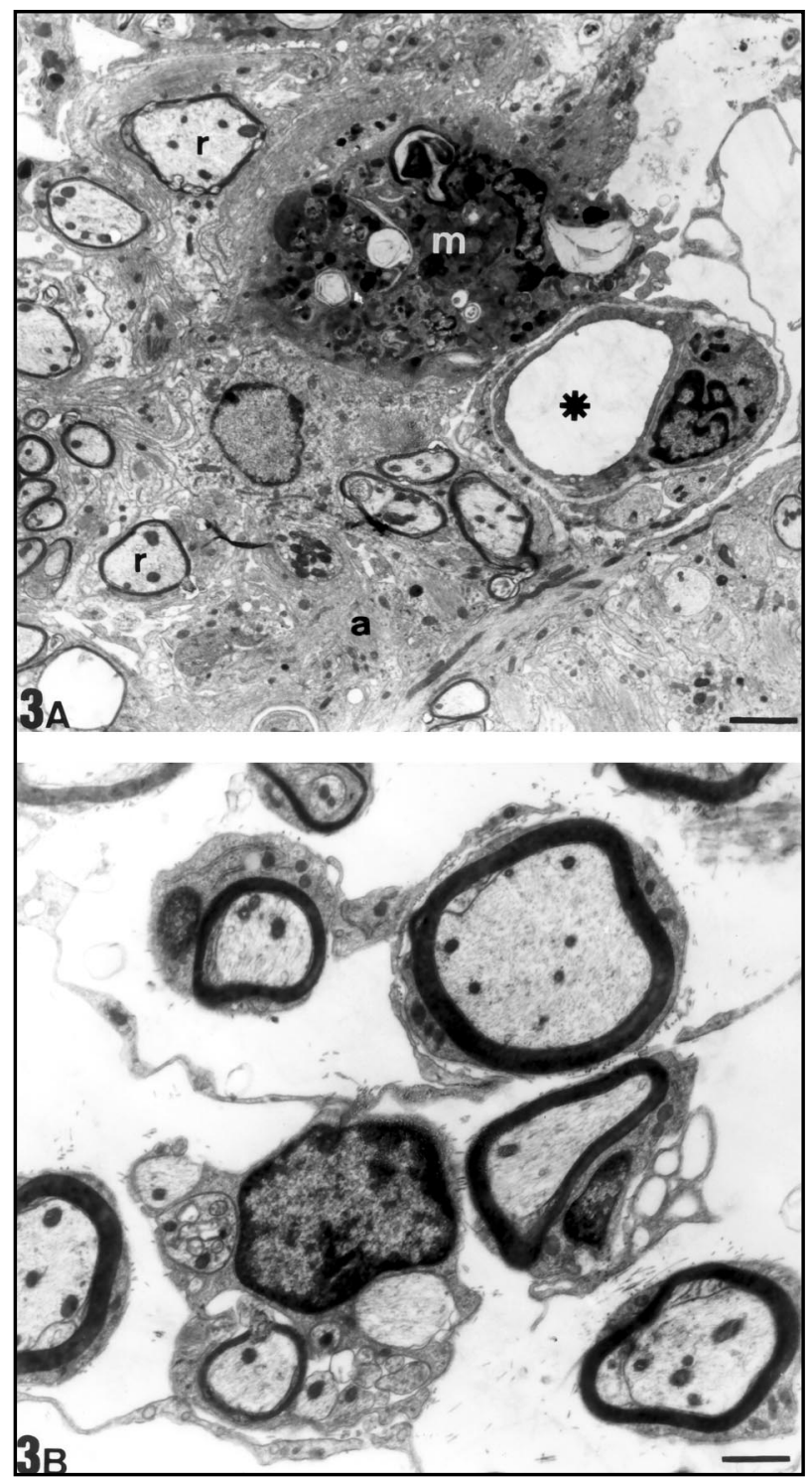

Fig 3. A) Área contendo processos astrocitários hipertrofiados (a) junto a axônios remielinizados por oligodendrócitos ( $r$ ), macrófago $(m)$ contendo mielina em diferentes estágios de degradação e capilar neoformado (*). B) Células de Schwann em adiantado estágio de remielinização. Lesão de 31 dias. Grupo I. Micrografias eletrônicas. A) Barra = 2,2 $\mu \mathrm{m} ; B$ ) Barra =0,96 $\mu \mathrm{m}$.

áreas de espaço extracelular expandido da periferia, onde persistiam restos mielínicos e macrófagos. Algumas já exibiam adiantado estado de remielinização; outras apresentavam longos processos envolvendo vários axônios ainda nus. As células piais, presentes principalmente ao redor dos vasos sangüíneos, formavam conjuntos compactos de dimensões variáveis, muitas vezes aprisionando em cavidades axônios relacionados com células de Schwann ou contactando macrófagos em atividade fagocitária. Estruturas de membrana semelhantes a desmossomos apareciam entre células meníngeas 


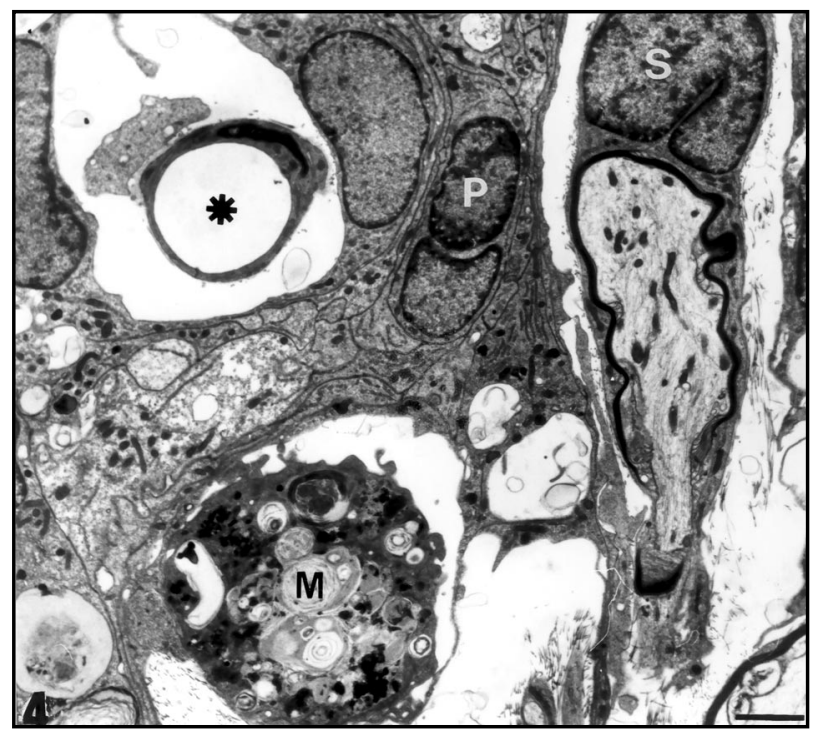

Fig 4. Cordões de células piais infiltrantes $(P)$ entre célula de Schwann (S) em processo de remielinização, macrófago ativado (M) e capilar neoformado (*). Lesão de 31 dias. Grupo I. Micrografia eletrônica. Barra = 2,2 $\mu \mathrm{m}$.

adjacentes, algumas das quais mostravam indícios de fagocitose de restos mielínicos. Linfócitos não foram mais encontrados.

Aos 31 dias pós-injeção do $\mathrm{BE}$, o reparo das bainhas perdidas foi identificado apenas na periferia, enquanto a área central conservava a presença de macrófagos de citoplasma carregado com restos mielínicos e enormes quantidades de membranas derivadas de mielina. Foram ainda observados, em localização periférica, axônios dotados de delgadas bainhas de origem oligodendroglial (Fig 3A) ou de bainhas mais espessas (Fig 3B) (e até excessivas para o diâmetro axonal) produzidas por células de Schwann, ninhos ou cordões de células piais (Fig 4), axônios desnudos agrupados ou separados por processos astrocitários, assim como células de Schwann envolvendo vários axônios de pequeno diâmetro. Oligodendrócitos e processos astrocitários hipertróficos eram ainda visualizados em áreas de membranas derivadas de mielina persistentes.

\section{Observações morfológicas no grupo III}

(injetados com salina e tratados com $D x$ )

Dos 7 aos 15 dias pós-injeção de solução salina, foram identificadas, à microscopia de luz, pequenas lesões de aspecto espongiótico na ponte, atribuídas ao trajeto da agulha da seringa de Hamilton e à deposição do volume de 10 microlitros na cisterna basal. Os cortes ultrafinos revelaram discreta presença de macrófagos em atividade de retirada de restos mielínicos no local, o qual mostrava espaço extracelular focal e levemente distendido, contendo mielina na forma de lamelas desprendidas e até como redes de membranas dela derivadas. Eram ainda encontradas poucas fibras nervosas em degeneração, bem como alguns axônios desprovidos de mielina, embora sem identificar-se evidência de perda de células da macróglia.

\section{DISCUSSÃO}

Os eventos celulares do processo remielinizante após desmielinização induzida por BE têm sido exaustivamente relatados no SNC ${ }^{2-12}$. De forma resumida, pode-se dizer que o tratamento com Dx pós-injeção do gliotóxico forneceu resultados quase idênticos àqueles obtidos com o citotóxico ciclofosfamida de estudo anterior ${ }^{11}$, no qual evidenciouse atraso no reparo mielínico com remielinização oligodendroglial lentificada, claro predomínio de axônios desmielinizados, escassa neovascularização, poucos linfócitos infiltrantes e presença de enormes quantidades de restos de mielina no centro da lesão. A ciclofosfamida não pareceu, entretanto, alterar o padrão de resposta astrocitária, nem a atividade invasiva e remielinizante das células de Schwann pós-injeção do BE.

Nos animais tratados com Dx, o achado morfológico mais proeminente no centro lesional foi também a presença de profusas membranas derivadas de mielina até 31 dias pós-injeção do gliotóxico, sugerindo uma lenta atividade dos macrófagos na remoção dos restos mielínicos, tal como descrito pela primeira vez em ratos Wistar normais por Graça e Blakemore ${ }^{5}$. Estes autores encontraram variação no processo de desmielinização induzida por BE na substância branca da medula espinhal e diferenças na velocidade da remielinização subseqüente. Enquanto, em algumas lesões ou áreas dentro de lesões, os restos mielínicos eram rapidamente processados por macrófagos e os axônios prontamente remielinizados por células de Schwann invasivas (lesões de tipo I ou rápidas), em outras de mesma idade, a mielina era transformada em redes membranosas que persistiam por longos períodos de tempo ao redor de axônios desmielinizados e poucos macrófagos (lesões de tipo Il ou lentas). A grande maioria das lesões lentas se desenvolvia em animais injetados com baixa dose de $B E$, sugerindose que uma resposta inflamatória de baixa intensidade não representava estímulo suficiente para a rápida entrada de macrófagos na área ou para a remielinização ${ }^{5}$.

No presente estudo, diferentemente do descrito 
por Graça e Blakemore ${ }^{5}$, nem sempre a ocorrência das membranas derivadas de mielina em lesões induzidas pelo BE mostrou-se relacionada a uma aparente redução no número de macrófagos ativados, parecendo indicar que o tratamento com Dx tenha apenas adiado o processo de retirada dos restos mielínicos. A presença de abundantes restos de mielina em áreas de desmielinização contendo macrófagos ativados foi descrita também na medula espinhal de ratos velhos ${ }^{13}$, persistindo por até 30 dias após injeção de lisolecitina, o que foi atribuído à menor resposta macrofágica supostamente exibida por tais animais. Supõe-se que o estímulo quimiotático desempenhado pelas bainhas em degeneração sobre as células fagocíticas seja transitório, uma vez que, na ausência de uma resposta macrofágica adequada, as mesmas parecem perder seu conteúdo lipídico, porém mantendo o arcabouço protéico, o qual supostamente se revela pouco atrativo para as células fagocíticas ${ }^{14}$.

O atraso macrofágico observado no presente trabalho pode ser compreendido como resultado da ação antiinflamatória exercida pela Dx, capaz de promover prolongada monocitopenia mediante sua administração regular, comprometendo a pronta exsudação de macrófagos para o tecido nervoso agredido com BE. À medida que ocorre a diminuição da população macrofágica de origem sangüínea no SNC, as células microgliais residentes tenderiam a tornar-se as principais encarregadas pela remoção dos restos mielínicos, abandonando seu estado normal de quiescência logo após a indução do trauma ${ }^{15,16}$. Entretanto, a retirada da mielina pela micróglia ativada parece representar um processo de mais longa duração. Sabe-se que, em situações de dano à barreira hematoencefálica com invasão do encéfalo por macrófagos hematógenos, o aparecimento de células fagocíticas contendo gotículas lipídicas acaba ocorrendo mais rapidamente ${ }^{17}$. A origem dos macrófagos presentes nas lesões não pode, porém, ser identificada em função da inexistência de marcadores fenotípicos específicos que permitam distinguir, em situações de injúria nervosa, as células microgliais ativadas e os macrófagos de origem sangüínea infiltrantes ${ }^{15-18}$.

Estudos desenvolvidos por Triarhou e Herndon ${ }^{19,20}$ compreenderam tentativas de modulação farmacológica dos processos desmielinizante e remielinizante empregando o modelo tóxico da lisolecitina, capaz de exercer uma ação detergente sobre as bainhas de mielina e de assim induzir intensa resposta macrofágica local. Produtos dessa reação, por sua vez, amplificariam o processo inflamatório originalmente desencadeado, resultando em mais perda mielínica. Em tais experimentos, o uso por 7 dias de ciclofosfamida, previamente à injeção de lisolecitina na medula espinhal de ratos adultos, revelou suprimir a inflamação tecidual e acelerar a remielinização. Já a administração por duas semanas de Dx ( $3 \mathrm{mg} / \mathrm{kg} / \mathrm{dia}$ ) após a injeção de lisolecitina resultou também em redução da área desmielinizada, porém retardando o processo de reparo mielínico ${ }^{19}$. Por outro lado, o bloqueio na atividade macrofágica, obtido mediante pré-tratamento com pó de sílica, deprimiu a ação fagocítica mononuclear no local da lesão, com atraso na retirada dos restos mielínicos, mas sem aparente efeito no processo remielinizante ${ }^{19,20}$.

Em nosso estudo, a administração prolongada de Dx iniciada imediatamente após a injeção do BE mostrou não ter reduzido a área desmielinizada, o que difere dos experimentos envolvendo distintas drogas no modelo da lisolecitina. Nestes, ciclofosfamida, azatioprina, Dx e pó de sílica pareceram exercer efeito depressor comum sobre o recrutamento monocitário e sobre a exsudação macrofágica, com isso reduzindo a resposta inflamatória e a extensão da desmielinização observada. Tal fato sugere que, no modelo da lisolecitina, adicionalmente à participação dos macrófagos na retirada das bainhas desprendidas, as células fagocíticas contribuiriam de forma importante para a amplificação do processo de desmielinização inicial ao promoverem dano mielínico acidental (bystander), a partir da liberação de produtos com efeito lítico direto sobre as bainhas ou sobre as células gliais no curso da reação inflamatória. No modelo do BE, porém, já que a supressão da função macrofágica pela Dx não pareceu exercer efeito notável sobre a extensão da desmielinização, o processo desmielinizante parece resultar mais da ação gliotóxica primária do agente do que de dano secundário resultante da liberação de produtos macrofágicos.

Adicionalmente, a morosidade na retirada dos restos celulares pós-injeção do BE foi acompanhada por marcado retardo no reparo geral da lesão e, sobretudo, por atraso da função oligodendroglial de reconstrução das bainhas perdidas. Esta constatação aproxima-se daquela realizada por Reynolds e Wilkin ${ }^{7}$, que relataram a ausência de significante remielinização no tronco encefálico em áreas onde persistiam grandes quantidades de restos mielínicos. Comparativamente aos animais imunocompetentes, aqueles tratados com Dx apre- 
sentaram menor número de células da linhagem oligodendroglial nas margens da lesão.

Alguns estudos ressaltam que uma rápida remielinização mostrava-se geralmente acompanhada de intensa resposta astrocitária, bem como de uma pronta remoção dos restos mielínicos, sugerindo que a presença de macrófagos apropriadamente ativados permitiria uma maior acessibilidade das células mielinogênicas aos axônios ${ }^{5,21}$. Macrófagos e astrócitos permitiriam então a existência de um meio repleto de citocinas e de fatores de crescimento, possibilitando uma eficiente remielinização ${ }^{18}$. Em contrapartida, muitos desses fatores poderiam também exercer efeitos negativos ao reparo tissular. Nesse contexto, as interações possíveis entre todas as moléculas secretadas no meio lesional revelam-se extremamente complexas, sendo difíceis de serem elucidadas com o uso de modelos in vivo, muito embora o efeito global, seja positivo ou negativo, possa ser inferido pela velocidade de ocorrência do processo remielinizante.

Frente ao pobre reparo mielínico observado após administração prolongada de cuprizone a camundongos, Ludwin ${ }^{22}$ sugeriu, pela primeira vez, que uma fraca resposta inflamatória poderia ser a causadora de uma ineficiente remielinização, por talvez representar um estímulo menos potente à mitogênese oligodendroglial. Apoio complementar à hipótese de que a inflamação desempenha efeitos gerais benéficos ao reparo mielínico pode ser encontrado em experimentos envolvendo transplantes de células gliais ${ }^{23}$, nos quais foi verificado que a resposta inflamatória associada à rejeição de xenoenxertos representava um potente estimulante à remielinização endógena. Assim sendo, é provável que o meio inflamatório contenha, além de moléculas com potencialidade de infligir dano às células mielinogênicas, outros fatores cujos efeitos sejam predominantemente de auxílio ao reparo das bainhas perdidas e até mesmo de neutralização dos produtos capazes de causar dano às mesmas, resultando, no balanço final de influências benéficas e deletérias da inflamação, mais em estimulação do processo remielinizante do que em prejuízo ao mesmo ${ }^{11}$.

Uma vez que a origem dos oligodendrócitos remielinizantes após episódios de desmielinização pode ser atribuída à migração e à divisão mitótica daqueles sobreviventes nas margens da lesão ${ }^{24-26} \mathrm{e} / \mathrm{ou}$ à proliferação e diferenciação das células progenitoras bipotenciais O/2A adultas, existentes em estado quiescente na substância branca do SNC adulto $^{27}$, pode-se também imputar o prejuízo no reparo mielínico nos animais tratados com $D x$ a possíveis efeitos antiproliferativos da droga sobre tais populações celulares, resultando em menor número de células capazes de reconstruir as bainhas perdidas após injeção do BE. Concordante com tal hipótese, os glicocorticóides têm-se mostrado capazes de inibir a proliferação de células progenitoras oligodendrogliais (células NG2+) em várias regiões da substância branca e cinzenta do SNC de ratos adul$\operatorname{tos}^{28}$. Uma vez que a proliferação de tais células representa um papel-chave no processo remielinizante, este achado sugere a possibilidade de que o emprego da Dx exerça efeitos negativos na resposta reparadora do tecido nervoso pós-trauma no SNC. Outros relatos têm confirmado a ocorrência de efeitos inibitórios pós-administração de glicocorticóides sobre a mielinização, sobre a gênese de oligodendrócitos e sobre a expressão de GFAP ${ }^{29}$.

No presente estudo, no entanto, apesar da constatação de algumas áreas centrais desprovidas de processos astrocitários, não houve qualquer evidência de interferência pela Dx no comportamento dos astrócitos. Assim, processos espessados dessas células foram encontrados entre axônios desmielinizados, remielinizados e às vezes em degeneração, assim como entre membranas derivadas de mielina persistentes. Estes achados questionam a relação sugerida por Gilson e Blakemore ${ }^{13}$ de que a pobre resposta astrocitária descrita em ratos velhos é resultante da pouco intensa resposta macrofágica constatada nesses animais.

Nossos resultados indicam que, muito embora macrófagos/micróglia ativada e astrócitos reconhecidamente sejam capazes de influenciar-se mutuamente, estabelecendo uma comunicação bidirecional através de fatores solúveis liberados (tais como IL-1, IL-6 e TNF- $\alpha)^{18}$, as respostas macrofágica e astrocitária podem apresentar-se também desvinculadas em sua expressão final, sob forma de diminuição da primeira com manutenção da segunda, sugerindo, assim, que outras variáveis estão também envolvidas no complicado cenário do reparo tecidual após episódio de desmielinização.

A menor presença de linfócitos (visualizados nas lesões dos 7 aos 11 dias) observada nos ratos tratados com Dx em relação aos imunocompetentes é igualmente consistente com a atividade imunossupressora da droga. Além disso, a menor neovascularização das lesões pode ser creditada também à interferência na atividade macrofágica provocada pelo tratamento, já que produtos macrofágicos, 
como IL-1 e TGF- $\beta$ 1, são reconhecidos por sua capacidade de induzir angiogênese $\mathrm{e}^{30}$. O desaparecimento dos linfócitos das lesões pelo emprego desse agente imunossupressor e antiinflamatório pode ainda ter, em parte, resultado da própria redução da secreção macrofágica de IL-1, uma vez que essa citocina parece colaborar de forma importante na proliferação das células T e na adesividade de linfócitos e monócitos ao endotélio vascular ${ }^{18}$.

A Dx não pareceu prejudicar a atividade infiltrativa e proliferativa das células piais, as quais, por razões obscuras, formavam muitas vezes arranjos mais extensos do que os encontrados nos animais imunocompetentes ${ }^{11}$. Ainda, o comportamento das células de Schwann aparentemente não se mostrou prejudicado pela Dx, sendo, à semelhança dos ratos imunocompetentes, visualizadas bainhas espessas produzidas por tais células e, às vezes, até mesmo redundantes (redundant loops) em relação ao diâmetro axonal a partir dos 21 dias pós-injeção do BE.

Sabe-se que o atraso da remielinização encontrado com o uso da Dx não pode ser creditado unicamente à falha de uma reação inflamatória/macrofágica apropriada e/ou à interferência na divisão dos oligodendrócitos e de seus progenitores. $\mathrm{O}$ processo remielinizante é extremamente complexo, compreendendo várias etapas essenciais, desde a proliferação de células mielinogênicas, seu recrutamento do tecido circundante normal, sua migração às áreas desmielinizadas e finalmente a formação definitiva de novas bainhas de mielina. Pela complexidade do processo torna-se difícil identificar com precisão como e em que estágios a Dx interfere no processo de restauro das bainhas perdidas de maneira a retardá-lo.

\section{REFERÊNCIAS}

1. Miller DJ, Rodriguez M. Spontaneous and induced remyelination in multiple sclerosis and the Theiler's virus model of central nervous system demyelination. Microsc Res Techn 1995;32:230-245.

2. Yajima K, Suzuki K. Demyelination and remyelination in the rat central nervous system following ethidium bromide injection. Lab Invest 1979;41:385-392.

3. Yajima K, Suzuki K. Ultrastructural changes in oligodendroglia and myelin sheats induced by ethidium bromide. Neuropathol Appl Neurobiol 1979;5:49-62.

4. Blakemore WF. Ethidium bromide induced demyelination in the cord of the rat. Neuropathol Appl Neurobiol 1982;8:365-375.

5. Graça DL, Blakemore WF. Delayed remyelination in rat spinal cord following ethidium bromide injection. Neuropathol Appl Neurobiol 1986;12:593-605.
6. Graça DL. The presence of lymphocytes in a toxically induced demyelinating process of the central nervous system. Micr Eletr y Biol Cel 1988;12:17-22.

7. Reynolds R, Wilkin GP. Cellular reaction to an acute demyelination/remyelination lesion of the rat brain stem: localisation of GD, ganglioside immunoreactivity. J Neurosci Res 1993;36:405-422.

8. Gevehr CG, Graça DL, Pereira LAVD. Desmielinização e remielinização após múltiplas injeções intramedulares de brometo de etídio em ratos Wistar. Arq Neuropsiquiatr 1997;55:189-202.

9. Pereira LAVD, Dertkigill MS, Graça DL, Cruz-Höffling MA. Dynamics of remyelination in the brain of adult rats after exposure to ethidium bromide. J Submicrosc Cytol Pathol 1998;30:341-348.

10. Bondan EF, Lallo MA, Graça DL. Efeitos do brometo de etídio no tronco encefálico de ratos Wistar imunossuprimidos com ciclosporina. Coleção Cadernos de Estudos e Pesquisas UNIP 1998:1-46.

11. Bondan EF, Lallo MA, Sinhorini IL, Pereira LAVD, Graça DL. The effect of cyclophosphamide on the rat brainstem remyelination following local ethidium bromide injection in Wistar rats. J Submicrosc Cytol Pathol 2000;32:603-612.

12. Graça DL, Bondan EF, Pereira LAVD, Fernandes CG, Maiorka PC. Behaviour of oligodendrocytes and Schwann cells in an experimental model of toxic demyelination of the central nervous system. Arq Neuropsiquiatr 2001;59:358-361.

13. Gilson J, Blakemore WF. Failure of remyelination in areas of demyelination produced in the spinal cord of old rats. Neuropathol Appl Neurobiol 1993;19:173-181.

14. Offner H, Konat G. Myelin changes induced by incubation of brain slices with serum. Neurochem Int 1983;5:45-49.

15. Jordan FL, Thomas WE. Brain macrophages: questions of origin and interrelationship. Brain Res Rev 1988;13:165-178.

16. Thomas WE. Brain macrophages: evaluation of microglia and their functions. Brain Res Rev 1992;17:61-74.

17. Bignami A, Dahl D. Glial cells in the central nervous system and their reaction to injury. Austin: RG Landes 1994:1-108.

18. Benveniste EN. Cytokines: influence on glial cell gene expression and function. In: Blalock JE. (ed) Neuroimmunoendocrinology. Basel: Karger 1992:106-153.

19. Triarhou LC, Herndon RM. The effect of drugs on experimental remyelination. Neurology (Suppl. 1) 1984;34:578.

20. Triarhou LC, Herndon RM. Effect of macrophage inactivation on the neuropathology of lysolecithin-induced demyelination. Brit J Exp Pathol 1985;66:293-305.

21. Jeffery ND, Blakemore WF. Remyelination of mouse spinal cord axons demyelinated by local injection of lysolecithin. J Neurocytol 1995;24:775-781.

22. Ludwin SK. Chronic demyelination inhibits remyelination in the central nervous system. An analysis of contributing factors. Lab Invest 1980;43:382-387.

23. Blakemore WF, Crang AJ, Franklin RJM, Tang K, Ryder S. Glia cell transplants that are subsequently rejected can be used to influence regeneration of glial cell environments in the CNS. Glia 1995;13:79-91.

24. Herndon RM, Price DL, Weiner LP. Regeneration of oligodendroglia during recovery from demyelinating disease. Science 1977;195:693-694.

25. Raine CS, Scheinberg L, Waltz JM. Multiple sclerosis. Oligodendrocyte survival and proliferation in an active established lesion. Lab Invest 1981;45:534-546.

26. Arenella LS, Herndon RM. Mature oligodendrocytes. Division following experimental demyelination in adult animal. Arch Neurol 1984;41:1162-1165.

27. Wolswijk G, Noble M. Cooperation between PDGF and FGF converts slowly dividing $\mathrm{O}-2 \mathrm{~A}$ adult progenitor cells to rapidly dividing cells with characteristics of O-2A perinatal progenitor cells. J Cell Biol 1992;118:889-900.

28. Alonso G. Prolonged corticosterone treatment of adult rats inhibits the proliferation of oligodendrocyte progenitors present throughout white and gray matter regions of the brain. Glia 2000;31:219-231.

29. Jung-Testas I, Schumacher M, Robel P, Baulieu EE. Actions of steroid hormones and growth factors on glial cells of the central and peripheral nervous system. J Steroid Biochem Molec Biol 1994;48:145-154.

30. Perry VH, Andersson PB, Gordon S. Macrophages and inflammation in the central nervous system. TINS 1993;16:268-273. 